\title{
Being Social @ Work: Designing for Playfully Mediated Social Awareness in Work Environments
}

\author{
Dhaval Vyas', Marek R. van de Watering ${ }^{2}$, Anton Eliëns ${ }^{2}$ and Gerrit C. van \\ der Veer ${ }^{3}$ \\ I Human Media Interaction Group, Twente University, \\ the Netherlands \\ 2 Deptartment of Computer Science, Vrije Universiteit Amsterdam, \\ the Netherlands \\ 3 School of Computer Science, Open Universiteit, \\ Valkenburgerweg, the Netherlands
}

\begin{abstract}
Awareness within work environments should not be seen limited to important work-related information, activities and relationships. Mediating somewhat casual and engaging encounters related to non-work issues could also lead to meaningful and pleasurable experiences. This paper explores a design approach to support playfully mediated social awareness within an academic environment. Using ethnographic exploration and understanding the current and aspired practices, we provide details of two broad (and some times overlapping) categories of interaction for supporting and enhancing playfully mediated social awareness amongst staff members: 1) Self-Reflections and 2) Casual Encounters. We implement these two categories of interaction in an intelligent, asynchronous, large screen display called Panorama, for the staff room of our computer science department. Panorama attempts to mediate noncritical, non-work related information about the staff-members in an engaging manner to enhance social awareness within the department. We particularly emphasize on the soft design issues like reflections, belonging, care, pleasure and playfulness utilized in our design approach. The result of a two-phase assessment study suggests that our conceptualization of social awareness and the Panorama application has the potential to be easily incorporated into our academic environment.
\end{abstract}

\section{Introduction}

Conceptualizing 'awareness' within public and private settings has been an important issue in Human-Computer Interaction (HCI) and Computer Supported Collaborative Work (CSCW) research. The term awareness, however, is ambiguous. 
Early technologies to support awareness - like media spaces [2], have often been specialized for mediating selective work related activities and relationships, through computationally integrated audio-video links between geographically dispersed coworkers $[7,14]$. In the initial media spaces, the use of videos to mediate awareness was criticized for its limited view-capturing possibilities supporting mainly face-toface communications, and for privacy related issues [12]. At the same time, it is debatable to what extent these systems could convey the precise awareness of other people, their activities or their contexts.

The scope of technology design is broadening with the growing interest and need to support personally meaningful, authentic, sociable and rich everyday experiences. The notion of mediated awareness has evolved from the objectively observable aspects encompassing mainly the peripheral settings to conveying subjective aspects such as love and intimacy $[1,21,34]$, playfulness $[1,12,28]$ and other related issues.

In big organizations, social awareness is sometimes neglected in the tension between heavy workloads, time clashes, a lack of social encounters between employees, and a lack of suitable platforms that allow one to construct and convey one's identity [3]. In this paper we provide details of our work on developing a design approach for playfully mediated social awareness within work environments. As Gaver defines [11], playfulness is about creating new perspectives, ideas, and goals, and exploring new ethical and aesthetic standpoints, and not only about entertainment or spending time. Playful systems allow users to playfully and artfully express their own creativity to establish curiosity, exploration and reflection as key values.

A main question that we answer in this paper is how we can design technologies for conveying non-work related, non-critical information about staff-members to enhance social awareness in an academic department. We start with an ethnographic exploration utilizing contextual interviews, naturalistic observations and cultural probes to understand staff members' current and aspired practices of being socially aware of others and of the environment as a whole. Our approach in the fieldwork was focused on understanding social interactions limited not only to work or routine activities but also sentimental, pleasure and play related acts. Based on the results of our fieldwork, we decided to focus on conveying two types of information that are unselective in the sense that they are somewhat open-ended and at the same time engaging, playful and explorative. They are: ability to have Self-Reflections (e.g. making other people aware about one's personal and professional interests), and Casual Encounters among the staff members (e.g. having a verbal or visual encounters in common areas). We implement these two categories of interaction in a large screen display called Panorama, situated in the staff-room of our department. The Panorama interface is inspired by notions of art and attempts to convey information about staff members in a compelling, and engaging way. Panorama supports an asynchronous, 'shared-initiative' interaction in which members can publish their personally meaningful messages (self-reflection) onto the system and, at the same time, the system can detect meaningful interactions amongst the members (casual encounters) and artfully represent them on the display.

In the rest of the paper, we first outline the background work that enabled us to conceptualize social awareness and especially focus on awareness related to nonwork activities. We then provide a brief description of the methods used in the 
fieldwork and some results. Utilizing the results we describe the design of Panorama and provide details of our assessment study. Finally, we discuss several design strategies utilized in our approach for enhancing non-critical social awareness in a work environment. We discuss several design issues like reflection, belonging, curiosity, embodiment and playfulness used in our design approach.

\section{Social Awareness}

Our aim in this section is to provide some background research on social awareness to conceptualize non-work related, non-critical awareness within the University environment. Schmidt [27] notes that the word 'awareness' is a highly elastic English word and can mean different things in different situations. In this paper, we will focus on a type of technology that supports awareness between different people (office colleagues, family members, friends, lovers, etc.) and not on the technology that is aware of its own and its surrounding states and reacts accordingly - the context-aware systems [e.g. 6, 15]. The former can be categorized as technology for social awareness, since the focus is on supporting relationship between people either for productive (e.g. in the work environments) or for non-productive causes (e.g. in the domestic environments). We will provide an overview of early work on social awareness and point to new developments of the concept in non-work related situations.

\subsection{Early Work on Social Awareness}

The earlier technologies that were used to convey awareness through closely coupled audio-video links between offices were termed 'media spaces' [2, 7, 14]. Their initial use was to connect work between geographically dispersed offices and work environments. The main expected benefit of using media spaces was to support productivity in work environments by creating possibilities to engage in taskoriented conversations from a distance and, at the same time, to have a general orientation to the presence and activities of colleagues at the other end. Awareness from this perspective is defined as the following:

"Awareness involves knowing who is 'around', what activities are occurring, who is talking with whom; it provides a view of one another in the daily work environments. Awareness may lead to informal interactions, spontaneous connections, and the development of shared cultures - all important aspects of maintaining working relationships which are denied to groups distributed across multiple sites."

- Dourish and Bly [7, p.541]

Through media spaces, it was assumed that geographically dispersed office members would work as if they were at the same place. Unfortunately, these assumptions never materialized [27]. Most awareness systems developed to support the work environments focused on the very aspect of productivity in users' everyday work life. In some recent examples of awareness systems [e.g. 24, 26, 33] awareness is supported through indications of the presence of colleagues, availability of their 
biography, their project descriptions, information about their daily schedules and office calendars.

\subsection{Social Awareness beyond Work-Related Activities}

With new business needs and emergence of novel computing technologies, the focus of technologically mediated awareness has shifted from only users' work environments to their everyday interactions. The scope of awareness has extended from the mere physical space of the users, to conveying users' emotions, love, social status and other broader social and cultural aspects. Gaver suggests that, as the context in which these (awareness) technologies are used changes, the form and ways to interact with these technologies should also change [12].

In domestic environments these technologies are used to convey, for example, emotional connections between distant lovers [5, 21, 31, 34], awareness within families $[18,19,32]$ and ways to keep in touch with family from a distance $[25,22]$. In public domains, these technologies are used to establish playfulness and evocations between strangers [1,12], developing social and cultural respect within a large community [13], and many others. Even in office environments these technologies are deployed for exchanging information about the moods and attitudes between co-workers $[29,30]$. All these systems embody certain assumptions about the basic objectives for conveying awareness, the information that should be conveyed and the media through which this might be conveyed.

\subsection{Conceptualizing Social Awareness}

Bødker and Christiansen [3] suggest that social awareness is a very subtle aspect of our overall awareness, which can be accessed only 'indirectly' through a granular understanding of space, mediators, human conduct and culture. Social awareness can only be felt; it cannot be seen or measured in a precise manner. To be aware of somebody we need to feel his or her presence in a somewhat temporary and subtle way. Because, if presence is too apparent we tend to take it for granted. These authors conceptualize social awareness as a conscious feeling of belonging, relatedness, and care, prompted by the environment.

Taking a sociological stand point, Glaser and Strauss [16] argue that the phenomenon of awareness is central to the study of interaction. They termed a notion of awareness context - "the total combination of what each interactant in a situation knows about the identity of the other and his own identity in the eyes of the others" [p.670]. They suggest that to understand the awareness phenomenon it is very important to see interactions in a broader context.

Glaser and Strauss's conceptualization leads to a reflective approach, which suggests that awareness technology should allow interactants to reflect on a threeway relationship of: "how I see myself", "how I see others" and "how others see me." A similar position is also taken by Bødker and Christiansen.

"...for social awareness to be prompted ' 1 ' must have the opportunity to be reflected in my environment, and ' $\mathrm{I}$ ' must be able to see how others are reflected, just as they must be able to see the reflections of 'me'."

- Bødker and Christiansen [3, p.10] 
We conceptualize social awareness as reflections that are supported by 'cues' and 'traces' of different activities in the department. "A trace of human activity is recognized as 'social' when it allows someone to acquaint themselves with others without receiving explicitly expressed information about them" $[3, p .6]$. These cues and traces users leave in the environment make it compelling and emotionally valuable for the next person. When the next person chooses the same environment, he intentionally or unintentionally adds his own cues and traces to the same environment that eventually would turn the physical settings into a social world. Sometimes, these vague and low-fidelity cues and traces might be valued more for community building than bold and high fidelity cues [12].

\section{Designing for Playfully-Mediated Social Awareness}

By playfulness we do not mean winning or loosing and turn-taking with a final result. Gaming systems like PS-2, Xbox, Gameboy or PC games are already covering a huge market of entertainment industry. But in our case, we do not see entertainment or playfulness being limited to exclusive devices. Following Gaver [11], we see users as active and creative beings for constructing their own entertainment. In this paper we offer a design concept for enhancing social awareness, which also has a playful side to it.

As a first step towards designing for playfully mediated social awareness in a colocated academic department, we sought to understand staff members' current and aspired practices of social awareness within the department. We carried out an ethnographic investigation utilizing naturalistic observations, contextual interviews and cultural probes. From the data gathered in our investigation, we found two main categories of interaction for being socially aware: Casual Encounters and SelfReflections. These two patterns of interaction were then implemented in a large screen display called Panorama. A two-phase assessment study of a prototype of our Panorama system showed that the concept of casual encounters and self-reflections could potentially serve well in our department.

\subsection{Ethnographic Field study}

We used a method called interaction analysis [20] to inform our ethnographic exploration. It is an interdisciplinary method to investigate interactions of human beings among themselves and with objects in their environment. Even though this technique was originally used for video analysis, it provides a number of useful foci for understanding the social awareness phenomenon in an academic environment. We focused our exploration on the following categories:

- Forms of awareness

- Activities of awareness

- Agents of awareness

- Places of awareness

- Contents of awareness 
Forms of awareness describe different methods of communication that are used for mediating awareness information. These can be either synchronous (e.g. face-toface, phone calls) or asynchronous (e.g. e-mail, instant messaging tools, post-it notes). The methods for communicating awareness information can be explicit providing direct indications or implicit leaving room for multiple interpretations.

Activities of awareness describe the type of activities within the environment that could mediate awareness information. These can be task-oriented (i.e. a routine work activity) or social in nature (i.e. lunch, coffee break). Often these activities overlap so it is important to take into account the possible relationships between different activities.

Agents of awareness are the people and the objects or artifacts within the environment that mediate awareness, directly or indirectly. People can be seen as individuals and also as constituting groups (e.g. research groups). In this case it is important to understand the roles that the ethical and political issues (e.g. position hierarchy) play in contributing to social awareness. We also need to take into account the role of students in forming social awareness within our educational environment.

Places of awareness, in a broad sense, describe the geographical as well as the 'social spaces' where interactions take place, including the hot spots of interaction. This can be seen as a multi-layered concept: personal vs. private spaces of staff members within an office, a floor, a building and the whole environment. Inherent to the observations made in this category of awareness is the question: "how does the spatial layout influence the structure of interaction?"

Contents of awareness refer to the actual information being mediated through different interactions. Contents of awareness can be staff members' activities, presence, social and political status, achievements, and so on. This can be explicit (i.e. a note saying that a person will be back at a certain time) and implicit (i.e. artifacts used as symbols or the information at a 'glance'). Both are open to different interpretations by different people, the implicit content being more so.

Using these categories as a base for our exploration, we used three methods: naturalistic observations, contextual interviews and cultural probes.

In the naturalistic observations, we used video and still cameras to capture staffmembers' activities in the staff-room, the printing-room, the canteen and other common areas where social communication happens. One of the authors spent several hours during a week and noted staff members' everyday activities and their social encounters. Using a video camera, we also followed some of our colleagues to get insights into their everyday interactions e.g. walking to the canteen, to the printer room and to the staff room.

Next, we carried our contextual interviews and arranged a cultural probes [13] study with 10 participants. Eight of the participants were the current staff members with a mixture of $\mathrm{PhD}$ students, senior academics, administrative and $\mathrm{PR}$ members. We also asked two bachelors students to participate in this study to get a broader perspective. These participants were selected based on their availability and willingness to participate in a 6 weeks long study.

In the contextual inquiry, we asked questions regarding their social dynamics. For example: What type of information would the staff members in our department like to know about other members? What types of information would they be willing 
to share with others? What are their privacy concerns? What common areas in the department do they use often to gather information about others? What are the common tools of communications they use outside their offices? Especially in the staff room, what are the most common activities performed by the members and how often? And lastly, how important is being socially aware of other members in the department? The information was recorded in an audio device and written notes were also taken.

In the cultural probes study, we provided participants with a collection consisting of a disposable camera, a set of color pencils, post cards, maps, drawing pencils, a marker, scissors, glue, set of post-it notes and three popular magazines in a probe package; and asked the participants to create a personalized workbook and a logbook of their activities. In the workbook there were some open-ended and some specific question about their everyday interactions within the department. Instructions were also provided about when they should use the camera or other materials.

\subsection{Fieldwork Findings}

In our investigation we found two broad categories interaction for being socially aware of others: Self-Reflections and Casual Encounters. In this paper we will not provide the detailed results of our study, we will briefly discuss our findings focusing only on these two categories. It is important to note that these two categories should not be seen as definitive and mutually exclusive but as broad concepts for informing design.

\subsubsection{Self-Reflections}

In the fieldwork we observed several attempts of staff-members to let others know about their identity either in groups or individually by providing information about their achievement, status and announcements. We term this type of interaction as self-reflections. Several artifacts and devices were used as a carrier for mediating information about self-reflection. These artifacts and devices included notice boards, staff-room door (Fig 1), printing room door, post-it notes attached to one's office door and other artifacts available in common areas.

The purpose of self-reflection varied from work-related to personal and even sentimental reasons. On the door of our staff room (Fig. 1) there were indications about staff members' personal achievement (e.g. winning in a city marathon), announcement of an event (e.g. music concert), provocative educational clips from magazines (e.g. Business Week), sharing some personal experiences (e.g. holiday postcards) and announcing birth of newborn babies. 


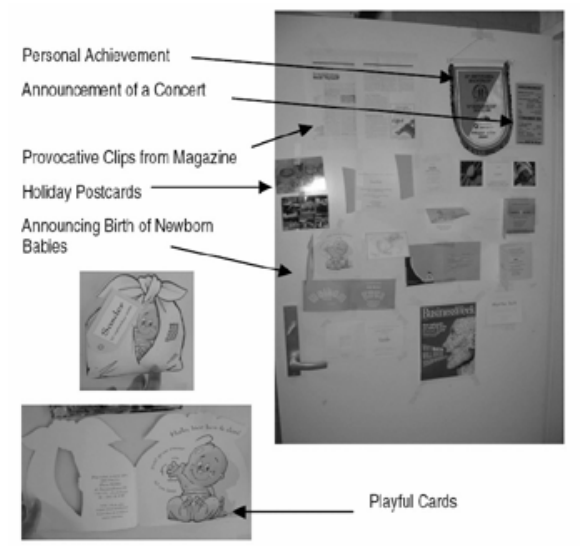

Fig. 1 Self-Refection objects found on the staff room door

The activity of self-reflection was mainly found in the form of asynchronous interaction, in which senders could publish their information in a physical or digital form and receivers would come across these via their habitual activities at work.

Sometimes email and web-based tools were also used for self-reflections. During the contextual interviews one participant mentioned about a web-based system that they used for making other people working on the same project aware of each other's activities. "I don't use it always but I publish my agenda on this web site so that other people can see what I am up to. Same way I can see other people's agendas and plans."

In the cultural probes and contextual interviews, we found that being socially aware of other members and students in the department was not the most important need, but all the participants agreed that if there is an opportunity they would really like it. Fig. 2 shows some examples of participants' expressions towards the overall department.

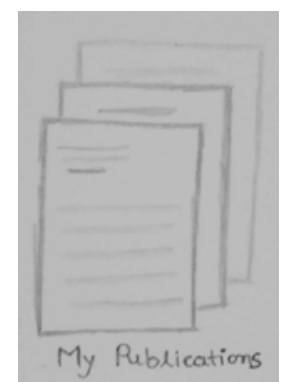

(a)

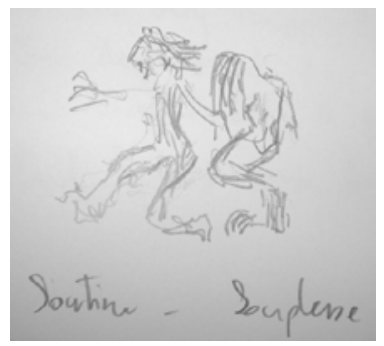

(b)

Fig. 2 Personal Expressions conveyed by staff members

Fig. 2 also provides indications about how the staff members wanted to convey their identity to the whole department. In some cases members wanted to convey their professional status (Fig. 2a), in others, they wanted to convey their personal thoughts (Fig. 2b). Fig. 2b is an art piece called-Souplesse originally created by a French artist Chaïm Soutine ${ }^{1}$ (1893-1943). The image has a great personal value for a senior researcher who came across it while he was a PhD student.

One of the flexibilities supported by self-reflections was its reconfigurability. Staff members could, at anytime, publish their information in a place that is publicly 
reachable and in the same way could take the information back if they wanted. We also observed the changes in the physical space because of the self-reflections. In one departmental secretary's office we found a huge collection of post-it notes stating different 'states of her presence' (see Fig.3). At any time when she needed to leave her office she would look for a ready-made post-it with relevance and stick it on her office door. This was a work specific activity, as she was responsible for about 20-30 staff members in the department.

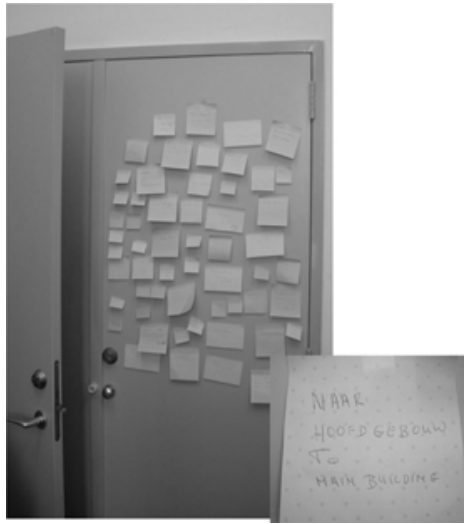

Fig. 3 An aware office door? A collection of Post-it notes found in an employee's office

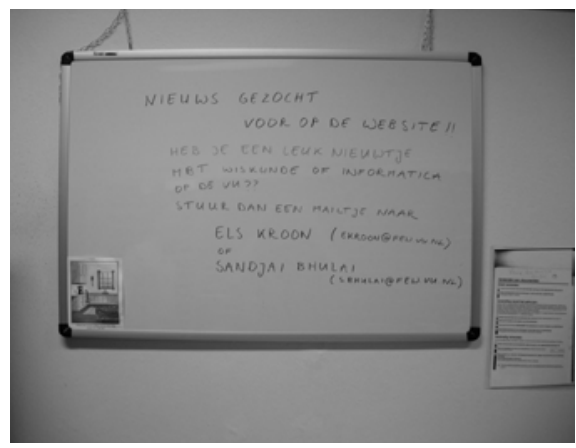

Fig. 4 A PR officer's announcement on the notice board in the staff room: It says, roughly, "Please, send us 'nice' news to put into our website"

On a different note, sometimes announcements were made on the main notice board of our staff-room. Fig 4 shows an announcement by the PR officer of the department. Email or other digital forms of communication were not used for this particular activity. It was assumed that the staff room is a central point of social and informal activities.

\subsubsection{Casual Encounters}

We found in our field study that most staff members had very limited time for explicit social interaction while working and that most encounters were initiated and defined by the "dynamics of the moment" (as one interviewee pointed out), thus by the context. Casual Encounter was a kind of interaction, where staff members, during their routine activities, interact with the other members and objects within the surroundings that provided hints and cues of social awareness. See Fig. 5 


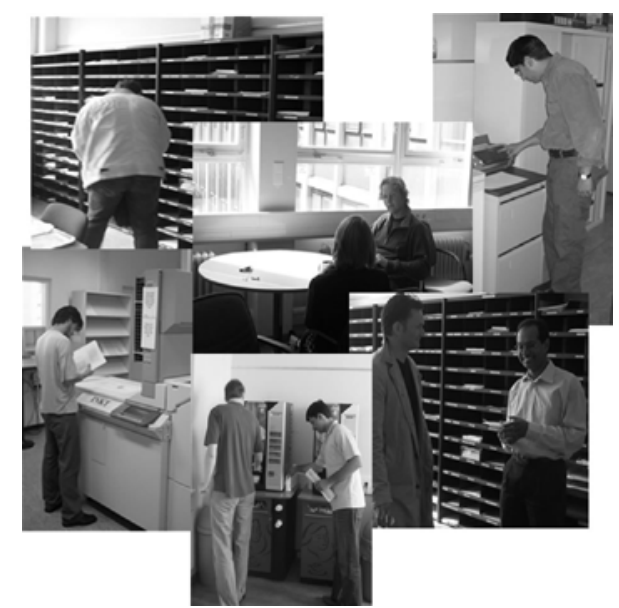

Fig 5 Everyday Casual Encounters. Direct and Indirect interaction with people and objects in the department.

Several examples of direct communication were seen, e.g. informal meetings in the staff-room, casual coffee-room chatting, chatting while queuing in the canteen and the printing room. Through these verbal and visual encounters staff members get information about others. These communications included information about professional activities as well as personal and social activities.
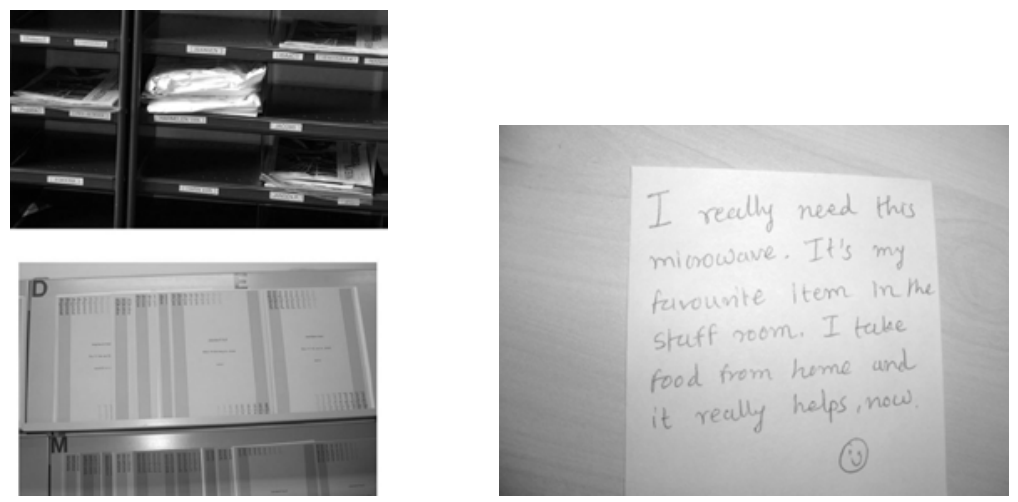

Fig. 6 Indirect mediation of awareness. Staff

Postboxes and Printing shelves.

Fig. 7 A scrap from a foreign employee.

There were also instances where indirect communication between staff members occurred. E.g. while checking the mail-box (see fig. 6) and faxes from the staff room and collecting prints from the printer room, staff members could see mail and prints belonging to other members. This can give an indirect indication about other members' presence or absence.

Maps used in the cultural probe study also gave a lot of indications about frequently visited places in the department and in the University. Most instances of casual encounters were closely related to the routine activities of staff members. These included coffee and lunch breaks and also some instantaneous activities like 
going into the staff room for using the fax machine or collecting post, for example. Fig. 7 shows a scrap from a foreign employee who used the microwave situated in the staff room.

The staff room was a common place for most social activities within the department, such as celebrations of different social events like employees' birthday and celebrating after getting funding of a new project. Normally, in this case the employee would use email to announce this amongst his group or friends. In some cases we observed play related activities. Some senior searchers liked playing cards with old friends to freshen their minds. The staff room played an important role in establishing relationships between staff members. In summary, our staff room played a role of social organizing.

\subsection{Panorama: Designing for Social Awareness}

For designing playfully mediated social awareness we treated the two interaction categories: Self-Reflections and Casual Encounters, as our design concepts. This means that the technology that we design should incorporate these two categories of interaction. To apply playfulness in the design we wanted to provide an opportunity for the staff members to artfully and creatively contribute to our departmental settings. It was evident from our study that the staff-room in our department was the centre for the most of social and informal activities. We intended to put a large screen display in our staff room that would allow staff members to receive socially meaningful information from the environment and to publish relevant information onto the display. The two design concepts were then implemented in a large screen display called Panorama. Fig. 8 shows a prototype version of the Panorama application.

As informed by our design explorations (section 3.2), Panorama utilizes information about Self-Reflections and Casual Encounters in the following way.

Self-Reflections are explicit user initiated interactions. For staff members this means that they can contribute towards the ongoing activities of the overall environment with their personal and non-critical information or data. Here, Panorama serves as a tool that allows staff members to support their social needs, such as sharing non-work related but highly sentimental news (e.g. announcing the birth of a new born child), personal achievements (e.g. best paper award), personal interests (e.g. favorite books, favorite conferences), etc. In this case, Panorama does not passively receive feeds from members. It in fact filters and alters contents and represents this in a manner to show co-occurrence with the real environment.

Casual Encounters are implicit system initiated interactions. In this case, Panorama proactively collects information about the ongoing activities within the department and offers resources of potential interest from the environment. Panorama serves as a mechanism by which staff members can be socially aware by knowing each other's presence, social events and relevant non-critical activities within the department. In this case, even though users passively receive information from the technology, they can actively comprehend the implications of their action (either alone or in groups) on the Panorama. 


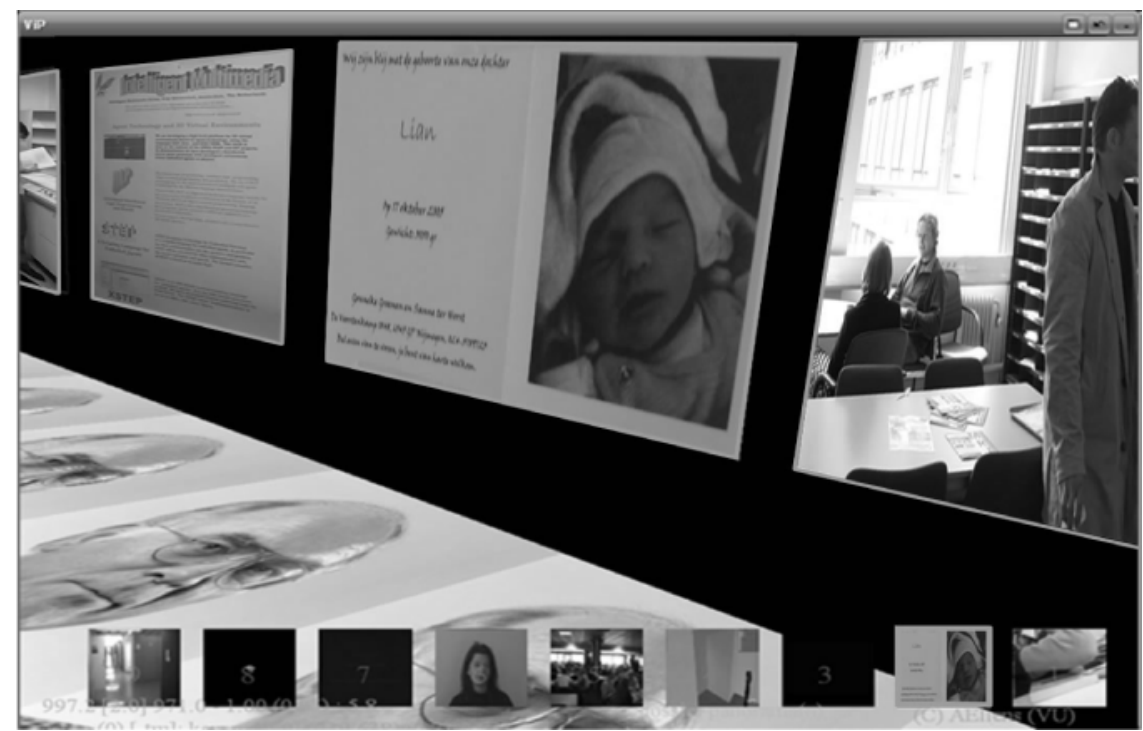

Fig. 8 The Panorama prototype representing an 'idle' environment in the department

Broadly speaking, Panorama receives explicit and implicit awareness information about the environment and the people and transforms this onto its display. The Panorama interface is like a virtual gallery, where on the wall and on the floor information about social awareness is presented. Both the frames on the wall and the floor are moving to indicate the passing of time. Fig. 8 represents the 'idle' environment when activity level is minimal. As activity level increases it transforms the representation first into the 'live' environment (representing the normal activity level) and then into to 'chaotic' environments (representing hectic activity level). We used motion and noise sensors to detect the activity levels in the common spaces like the staff room, the printing room and the main corridor. In both cases the activity level within the department is represented by the change of speed, color, abstractions (e.g. using shaders) and overlays of 3D objects and particles. Elsewhere [36] we have reported Panorama's representation logic in more details.

For designing Panorama we used a technology called ViP, which we previously developed for an augmented reality theatre production [9]. ViP (Virtual Poetry) is a complex 'representation' system based on DirectX9. It allows projection of live video feeds, digital video clips, texts and sequence of images on an immersive 3D space. The ViP system allows a variety of visual effects, including texture mapping of image feeds on 3D objects, overlays of multiple image textures, as well as particle systems with streaming image feeds projected on sprites.

The goal of the Panorama system is to enhance social awareness by providing interpersonal and rich information related to staff members and their everyday interactions in the department. The placement of the Panorama application in the staff room of our department should be seen as a facility to support staff members' creativity and playfulness and not as a tool that attempts solve problems. The Panorama interface in the staff-room will allow different users to speculate about 
what is happening in the department. This non-selective information will allow affective, engaging and reflective interactions among the members.

\subsection{Assessment of Panorama}

Methods for assessing technological aspects of a system may be impractical or unsatisfactory when evaluating systems that are meant to support subjective and interpersonal aspects [35], such as understanding their social awareness. Previous researches $[17,23]$ have shown that mixed-reality and artistic interfaces can better be evaluated using a combination of argumentation ('art criticism') and informal conversation with users. To validate our understandings of social awareness (as discussed in section 2.3) and to assess the effectiveness of Panorama in the staff room we organized our assessment in two phases.

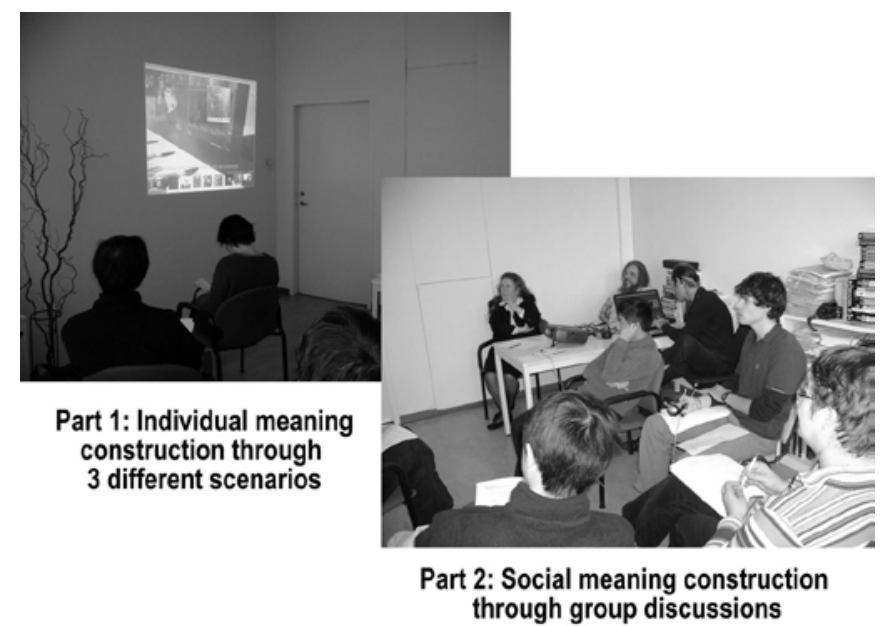

Fig. 9 Phase 1 of Panorama assessment (in a Laboratory)

In the first phase, we invited eight employees of our department to a laboratory. Without providing explicit information about Panorama, we demonstrated three different scenarios of Panorama, representing different environments in the department: Idle, Live and Chaotic. During the session we first asked them to individually write down: what Panorama represents, the difference between the three scenarios and the system's suitability in the department. After this we introduced some discussion points to observe their social meaning construction about the system. See Fig. 9. The discussions were recorded in an audio device and the transcripts of their written answers were also collected for further analysis of our system. 


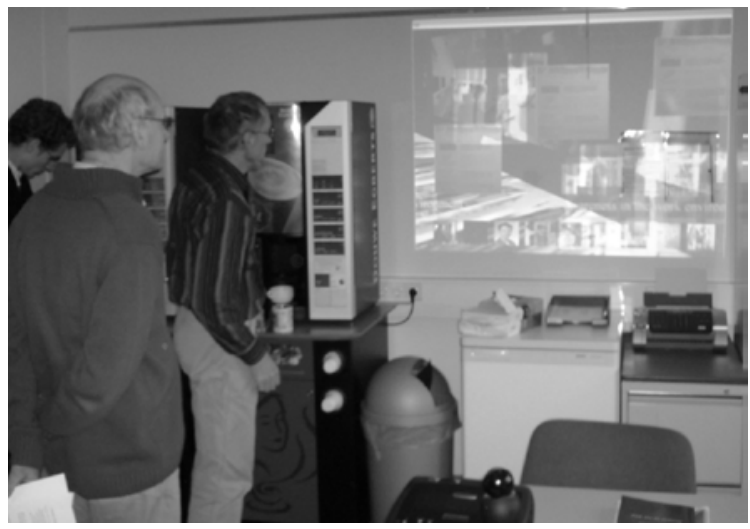

Fig. 10 Phase 2 of Panorama assessment (in the Staff room)

In the second phase, we installed the Panorama system in the staff room (see Fig. 10). The main purpose for this assessment was to observe the behaviors and reactions of staff members towards Panorama and check its effects in a natural environment. We asked questions similar to those in the lab assessment, but the whole experiment was situation dependant in the sense that the passers-by could comment on almost anything. We took notes of their comments and noted their behaviors.

Results: The lab assessment led to some interesting perspectives on Panorama. It was clear to all participants what Panorama was about. Some described it as, "it reflects the dynamics at our department", "it demonstrates what's the department in a virtual way", "a lazy way to get information about the department", and so on. Most participants could easily recognize the objects presented on the Panorama: posters, announcements, events, images of staff members, but it was difficult for them to make a clear narratives of the sequence of the presentation. The presentation of Panorama was appreciated by most participants. Some said, "it could also be used as a $P R$ resource to attract new students to the University." The three different scenarios of Panorama were also easily distinguishable into idle, live and chaotic environments. A tradeoff between information and impression was observed. Some participants (mainly students) appreciated the dynamic visuals, overlapping images and fast flow of information in scenario-3 (chaotic environment); compared to others (mainly senior staff members) who appreciated the slow but comprehensible flow of information in scenario-1 (idle environment). Scenario-2 (live environment) was considered to be the best by all the participants as it was a combination of a nice representation of the dynamic side of the department and still being informative.

In the staff room assessment, we noted that a main aspect of the Panorama system was curiosity. We did not explicitly invite anybody for this assessment. All participants came to the staff room to do their routine activities or take a short break from work. We observed that many of the viewers were curious to see their pictures in the department staff members' list. Interestingly, privacy did not seem to be an important issue. There were two reasons for this: first, Panorama provided noncritical information about staff members and mainly the information that was in fact 
published by the staff members themselves; and second, staff members (like other academics) were interested in conveying their status and identity. One of the viewers waited for some time to see himself on the big screen. Others commented, "I would like to see myself on the screen."

Did Panorama improve social awareness? We do not pretend to measure this effect. But we found that Panorama certainly increased curiosity and provided pleasant experiences amongst the participants, and to a certain extent improved their knowledge about the social environment. We believe that the social benefit offered by Panorama was a result of mainly the personal nature of the content and party the dynamic representation and its placement in the staff room. When installed in the staff-room, we observed that Panorama provided a reason for members to communicate about different ongoing activities in the department. E.g. a conversation: "Whose trophy is this?"... "I think its Jan's." An interesting thing about this example was that the same announcement of this person's achievement of 'winning in a city marathon' was already published on our staff room door (Fig. 1) but very few people knew it. When presented on Panorama it became a point of talk amongst the viewers. In this particular case, we observed that the viewers started talking about other aspects related to this instance.

\section{Discussion: Design Strategies for Playfully-Mediated Social Awareness}

Our design approach demonstrates the use of several interesting design strategies that are useful to enhance social awareness in the work environments.

Awareness as reflections. A main strategy that we applied in designing Panorama was the focus on reflections. Panorama allows its users to reflect on themselves and on other members of the department. In order to support this, it allows users to explicitly and implicitly leave cues and traces of their activities and preferences. Through the mechanism of self-reflection, for example, members in the department could know each other's personal and professional interests and the things one is up to. Panorama provides opportunities for viewing non-rational information that may trigger a commitment to reading and commenting on information that is related to the personal traces. It provides a common virtual space that allows members to know about each other.

Awareness as belonging. The panorama system embodies staff-members, their artifacts and their activities in the sense that their presence is reflected on the system. According to Fels [10] this type of embodiment can lead to an aesthetic feeling of belonging when users can relinquish the control over to the system. Panorama embodies the presence of the staff-member in a compelling and artistic way that leads to an emotional response of belonging to a community. In a big organization like our department, this could lead to social benefits even when it is difficult to establish face to face interactions with other members. This way panorama serves as a platform to support awareness as feeling of belonging.

Awareness as a choice. The use of an awareness system in the public domain may sometimes lead to privacy issues. Not all members may like a system that 
records their activities without notice. Organizational politics, organizational hierarchy and cultural diversity may even lead to the rejection of such an awareness system. Panorama utilizes social awareness in an academic environment as an option or a choice and not as an obligation: a person is present only if "he wants himself to be publicly known and present' [3]. As a mechanism to support self-reflections, the members can add their views and their personal information to the system making their presence and their views available to the community.

Awareness in embodiment. The representation dynamics on panorama cooccurs with the real-time activities in the department. E.g. when the activity level increases to a certain level the presentation of panorama gets changed to indicate the hectic work environment. This offer staff members a two-level communication mechanism. At the first level, staff members receive information about announcements, news, and so on from the different objects floating on the screen. And at the second level, the presentation of these objects provides indications of the kind of mood or emotion the department is going through, e.g. normal, idle, or chaotic.

Awareness in (playful) exploration. Unlike media spaces [2], where continuous, high quality video and audio links were provided to support awareness, the Panorama interface utilizes unselective, random information in the form of casual encounters and self-reflections. The Panorama interface provides information in a compelling manner, which makes the members explore possible facts hidden in the given information. Panorama provides a 'new way' of interacting with other staff members within the department. Members could intentionally leave cues and traces of their existence to make the environment playful. Nevertheless, this being unselective information allows open and rich awareness amongst the staff members. The randomness and non-critical aspect of Panorama allows staff members a sort of freedom-of-interpretations. Members can construct their own views and make their stories about the department based on the information provided on the Panorama screen.

Non-critical \& pleasurable awareness. Our focus has been on the non-critical awareness. Our staff room is used as a place to have a break from heavy work-load, stress and obligatory tasks related to work. During the field study, we observed members chatting and playing cards. Panorama adds a suitable technology in the staff room. Panorama does not focus on the precision of information but on how the information is experienced by the viewers through the traces it generates for supporting social awareness. Additionally, the information that is presented on the Panorama screen does not require full attention from the users. It is possible to ignore such information, and the receiver may choose not to interpret the details of someone else's traces in great detail.

Awareness beyond intelligence. The notions of seamlessness, disappearance and intelligence as propagated by ubiquitous computing [37] and ambient intelligence [8] are primarily based on the technological intelligence. Their technology-oriented conceptualization of context is very limited and sometime unachievable, especially when these approaches attempt to predict users' intentions and activities. Users' everyday encounters may involve interaction with many heterogeneous media and tools and users may adapt or interweave these to support their activities [4]. Additionally, viewing users as 'passive' receivers of information 
is an incomplete view. Panorama provides an opportunity for the staff members to be an active, playful and artful creator of their own environment. Panorama utilizes the intelligence aspect not to predict staff-members' behaviors or activities but for depicting them in an artistic way to enhance social awareness within a work environment.

\section{Conclusion}

Social awareness is in essence a relatively novel concept in the design of smart environments. This type of design profits from recent developments in domains like Ambient Intelligence [8], Ludic Design [11] and Virtual Art [17]. Combining inspirations from these fields allows an addition to the work environment that provides for causal encounters and self-reflections beyond the focus of business or work. This, in turn, will support, but not enforce, a deeper and more "personal" awareness of people and social events. Our artistically inspired design project resulted in understanding the value of design sensibilities like reflections, belonging, care, exploration, and playfulness. Our conceptualization and application for social awareness has demonstrated valuable outcomes.

\section{Acknowledgments}

This work was partially funded by a generous grant from Microsoft Netherlands. Most of the work reported here was carried out when the first author was associated with Vrije Universiteit Amsterdam. We would like to thank all our participants and colleagues. Thanks also go to Zeljko Obrenovic for his comments and Cees Visser for providing technical support.

\section{Reference}

I. K. Battarbee, N. Baerten, M. Hinfelaar, P. Irvine, S. Loeber, A. Munro, and T. Pederson, Pools and Satellites - Intimacy in the City. Proceedings of DIS' $(22$. ACM Press: NY, (2002), 237-245.

2. S. Bly, S. Harrison, and S. Irwin, Media Spaces: Bringing People Together in a Video, Audio, and Computing Environment. CACM, vol. 36, no. I, 1993, 28-46.

3. S. Bødker, and E. Christiansen, Computer support for social awareness in flexible work. Computer Supported Collaborative Work, Springer Netherlands, 15: 2006, 1-28.

4. M. Chalmers, and A. Galani, Seamful Interweaving: Heterogeneity in the Theory and Design of Interactive Systems. Proceedings of DIS'(1), ACM Press: NY, (2004). 243252.

5. H. Chung, C-H. Lee, and T. Selker, Lovers' Cup: Drinking interfaces as new communication channels. Proc of CHI')6. ACM Press: NY, (2006), 375-380.

6. K. Cheverst, N. Davies, K. Mitchell, A. Friday, and C. Efstratiou, Developing a contextaware electronic tourist guide: some issues and experiences. Proceedings of $\mathrm{CHI}()($ ). ACM Press: NY, (2000), 17-24. 
7. P. Dourish, and S. Bly, Portholes: Supporting Awareness in a Distributed Work Group. Proceedings of CHI'92. ACM Press: NY, (1992), 54I-547.

8. K. Ducatel, M. Bogdanowicz, F. Scapolo, J. Leijten, and J.C. Burgelman, Scenarios for Ambient Intelligence in 2010. ISTAG Final Report, (2001), IPTS, Seville, Feb.

9. A. Eliëns, Odyssee - explorations in mixed reality theatre. Proceedings of GAME'ON$N A^{\prime} 2006$, Naval Postgraduate School, Monterey, USA, Sept 19-21, 2006.

10. S. Fels, Designing Intimate Experiences. Proceedings of IUI'(14. ACM Press: NY, (2004), 2-3.

11. W. Gaver, Designing for Homo Ludens. I3 Magazine, No. 12, June, 2002, 2-6.

12. W. Gaver, Provocative Awareness. Computer Supported Collaborative Work. 11: Springer Netherlands, 2002, 475-493.

13. W. Gaver, T. Dunne, \& E. Pacenti, Design: Cultural Probes. Interactions, 6, I, ACM Press:NY, 1999, 21-29.

14. W. Gaver, A. Sellen, C. Heath, and P. Luff, One is not enough: Multiple views in a media space. Proceedings of INTERCHI'93. ACM Press: NY, (1993), 335-341.

15. H-W. Gellersen, M. Beigl, and H. Krull, The MediaCup: Awareness Technology embedded in an Everyday Object. Ist International Symposium on HUC'99, LNCS; Vol 1707, Springer, (1999), 308-310.

16. B.G. Glaser, and A.L. Strauss, Awareness Contexts and Social Interaction. American Sociological Review, Vol.29, No.5, 1964, 669-679.

17. K. Höök, P. Sengers, and G. Andersson, Sense and Sensibility: Evaluation and Interactive Art. Proceedings of CHI')3. ACM Press: NY, (2003), 241-248.

18. D. Hindus, S. Mainwaring, N. Leduc, A. Hagström, and O. Bayley, Casablanca: Designing social communication devices for the home. Proceedings of $\mathrm{CHI}(\mathrm{l})$. ACM Press: NY, (2001), 325-332.

19. H. Hutchinson, W. Mackay, B. Westerlund, B. Bederson, A. Druin, C. Plaisant, M. Beaudouin-Lafon, S. Conversy, H. Evans, H. Hansen, N. Roussel, B. Eiderbäck, S. Lindquist, and Y. Sundblad, Technology Probes: Inspiring Design for and with Families. Proceedings of CHI'(03. ACM Press: NY, (2003), 17-24.

20. B. Jordan, and A. Henderson, Interaction Analysis: Foundations and Practice. Journal of the Learning Sciences, 4: 1, 1994, 39-102.

21. J. Kaye, and L. Goulding, Intimate Objects. Proceedings of DIS'(4). ACM Press: NY, (2004), 341-344.

22. P. Markopolous, N. Romero, J. van Baren, W. IJsselsteijn, B. de Ruyter, and B. Farshchian, Keeping in Touch with the Family: Home and Away with the ASTRA Awareness System. Proceedings of CHI'(1)4. ACM Press: NY, (2004), 1351-1354.

23. M. Mateas, Expressive AI: A hybrid art and science practice. Leonardo, 34 (2), 2001, 147-153.

24. J. McCarthy, T. Costa, and E. Liongosari, UniCast, OutCast \& GroupCast: Three Steps Toward Ubiquitous, Peripheral Displays. In G. Abowd, et al. (Eds): Proceedings Of Ubicomp 2001, LNCS 2201, Springer-Verlag Berlin Heidelberg. (2001), 332-345.

25. E.D. Mynatt, J. Rowan, S. Craighill, and A. Jacobs, Digital family portraits: Providing peace of mind for extended family members. Proceedings of $\mathrm{CHI}^{\prime}() 1$. ACM Press: NY, (2001), 333-340.

26. J. Redström, T. Skog, and L. Hallnäs, (2000) Informative Art: Using Amplified Artworks as Information Displays. Proceedings of DARE'()(). ACM Press, NY, (2000), 103-114.

27. K. Schmidt, The problem with 'awareness': Introductory remarks on 'Awareness in CSCW'. Computer Supported Collaborative Work. 11 : Springer Netherlands, 2002, 285298.

28. A. Sellen, R. Harper, R. Eardley, S. Izadi, T. Regan, A. Taylor, and K. Wood, Situated Messaging in the Home. Proceedings of CSCW' $(66$. ACM Press: NY, (2006), 338-392.

29. P. Sengers, K. Boehner, S. David, and J. Kaye, Reflective Design. Proceedings of Aarhus-2005 conference on Critical Computing. ACM Press, NY, (2005), 49-58. 
30. N. Streitz, C. Röcker, T. Prante, D. van Alphen, R. Stenzel, and C. Magerkurth, Designing Smart Artefacts for Smart Environments. IEEE Computer, March, 2005, 4149.

31. R. Strong, and W. Gaver, Feather, scent, and shaker: Supporting simple intimacy. Proceedings of CSCW'96. ACM Press: NY, (1996), 29-30.

32. A. Taylor, L. Swan, R. Eardley, A. Sellen, S. Hodges, and K. Wood, Augmenting Refrigerator Magnets: Why Less is Sometimes More. Proceedings of NordiCHI'(06. ACM Press:NY, (2006), 115-124.

33. K. Tollmar, O. Sandor, and A. Schomer, Supporting social awareness (®) work: design and experience. Proceedings of CSCW'96. ACM Press: NY, (1996), 298-307.

34. F. Vetere, M. Gibbs, J. Kjeldskov, S. Howard, F. Mueller, S. Pedell, K. Mecoles, and M. Bunyan, Mediating Intimacy: Designing technologies to support strong-tie relationships. Proceedings of CHI'05. ACM Press: NY, (2005), 471-480.

35. D. Vyas, and G.C. van der Veer, Rich Evaluations of Entertainment Experience: Bridging the Interpretational Gap. Proceedings of 13th European Conference on Cognitive Ergonomics (ECCE-13). Zurich, Switzerland, (2006), 137-144.

36. D. Vyas, M.R. van de Watering, A. Eliëns and G.C. van der Veer, Engineering Social Awareness in Work Environments. Proceedings of HCl International 2007, Beijing, China, (in Press).

37. M. Wieser, The computer for the 21 st century. Scientific American, 9, (1991), 933-940. 